\title{
Influence of Weight Bearing Dorsiflexion (WBDF) on Ankle Injury History Among Semi-professional Recreational Basketball Players
}

\author{
Sameera P Senanayake $^{1 *}$, G. W. T. Premakumara ${ }^{2}$, P. P. Kodagoda ${ }^{2}$, M. H. A. Jayasekara ${ }^{2}$ \\ ${ }^{1}$ Department of Basic Sciences, Faculty of Allied Health Sciences, KDU \\ ${ }^{2}$ Department of Physiotherapy, Faculty of Allied Health Sciences, KDU
}

\section{* Corresponding Author email:}

sp.senanayake@kdu.ac.lk

Article History

Received: 07 July 2021

Accepted: 10 October 2021

Published: 07 November 2021

\section{Student(s) \\ - G. W. T. Premakumara \\ - P. P. Kodagoda \\ - M. H. A. Jayasekara}

Academic Year: 2020-21

Course Level: Bachelor

Course Name: Physiotherapy

Course year: Final Year

$\operatorname{Mentor}(s)$

- Dr Sameera P Senanayake

\section{ABSTRACT}

Ankle injuries are one of the most common occurrences in the field of sports. Weight bearing dorsiflexion range can be an effecting factor in ankle injuries. Weight bearing lunge test is used to assess weight bearing dorsiflexion. By using this test as a standard testing protocol, it is possible to minimize development of further sport related ankle injuries. But this test for basketball players with ankle injuries has not been studied yet. The current study will aim to examine the weight bearing dorsiflexion of basketball players related to their gender, ankle injury history and leg dominance. A quasi-experimental design study was conducted. Thirty-four (34) participants were recruited and initially and two (2) were excluded. 18 participants were male and 14 were female basketball players in Colombo Blues and Kotelawala Defence University basketball teams. The average of age of the sample was 21.8 years. Demographic data, information about training time, injury history of the participants was obtained using an interview administered assessment form. The Weight Bearing Dorsiflexion was measured using digital inclinometer. Findings indicated that the weight bearing dorsiflexion range is smaller than that of males $(p>0.05)$. There was a significant difference in weight bearing dorsiflexion and ankle injury history $(\mathrm{p}<0.01)$ among players. Significant differences were seen in influence in leg dominance to weight bearing dorsiflexion $(\mathrm{p}<0.05)$. This is the first study that is investigated weight bearing dorsiflexion among basketball players in Sri Lanka. No significant difference was found between gender and weight bearing dorsiflexion. A significant difference was determined between ankle injury history and weight bearing dorsiflexion. Furthermore, a significant difference was found in leg dominance and weight bearing dorsiflexion.

Keywords: Basketball, Weight bearing dorsiflexion, Lunge test 


\section{Introduction}

Basketball is one of the most popular sports in the world, invented by James Naismith more than a century ago [1]. Basketball is a fast sport which requires improved body composition, cardiorespiratory function and, high amounts of strength [1]. It is a sport which requires high physical activities such as repetitive jumps during games as well as training, abrupt changes in direction, running, acceleration and deceleration [1]. This high demand of physical activity and the constant need to make jumps puts a huge impact and strain on joints in the lower body, which could often lead to ankle injuries among these players. Lower limb injuries account up to $60 \%$ of total injuries in basketball. [2]. Research done by Cumps et al, [3] shows ankle sprain and knee overuse injuries are the most common type of injuries among senior basketball players. According to Gross et al, [4] the most common joint which is injured in basketball is the ankle joint among adult basketball players groups aged 25 and over. Ankle injuries are defined as damage of tissues, ligaments, tendons, or bones at the ankle joints [5]. These injuries occur when the joint is twisted or pressured too far out of its normal position leading to fractures, sprains, strains, tendon injury and subluxations. Sprain is the most common type of injury among athletes and sporting personal [6]. Sprains are referred to partial or complete tears in ligaments of ankle joint and usually occurs by excessive inversion on the plantar flexed in the weight bearing foot [6]. Ankle sprain can be divided as an inward reverse sprain and outward reverse sprain and there is a significant high risk of sustaining a lateral ankle sprain through outward reverse sprain [6]. Some of the symptoms of ankle injury includes severe pain, local swelling, tenderness, and joint hematoma resulting in subcutaneous congestion which leading to a limp.

Although basketball is not popular compared to cricket in Sri Lanka, it is still played to some extent in a competitive level mainly among schools and between institutions within the country. Considering the factors contributing to restrictions to participate in a basketball match, injuries are on the top. Once an injury occurred, the player will not be able to return to the sport for a considerable period, affecting the entire team and the competitiveness of the sport.

Research has indicated that players with ankle injury have reduced performances. However, range of motions in ankle joint can be changed with proper physiotherapy treatment. To our knowledge, no research has been conducted to find out the relationship between ankle injury histories and weight bearing dorsiflexion (WBDF) range in basketball players. In our research, we are hoping to analyze how WBDF, and limb dominance is affected by ankle injury history using the weight-bearing lunge test. With this in mind the objective of this study will be to determine the relationship between the ankle injury history, gender, and weight bearingdorsiflexion (WBDF) among recreational basketball players in Colombo district, Sri Lanka. The results of our study will assist the physiotherapists who work in the sports field to develop better training programs to improve performances among basketball players by managing WBDF range as needed. This research will help to improve the quality of performances in basketball players and fill the gap in literature which in a Sri Lankan context.

\subsection{Objectives}

- To identify the differences between gender in WBDF.

- To compare the difference in WBDF between basketball players with apresence and absence of ankle injury

- To compare the difference between the dominant and non-dominant limb

\section{Research Methodology}

\subsection{Study design}

This study uses a quasi - experimental design [7]. One of the researchers collected all data for one parameter who was blinded to limb status (injured/ uninjured) to minimize bias. All the limbs were assigned into experimental group according to gender and previous ankle injury [7]. Assuming with in subject design 
participant's dominant and non-dominant limbs were paired and the WBDF was compared. All uninjured limbs were assigned to compare $\mathrm{WBDF}$ with gender, assuming between subject design.

\subsection{Inclusion and exclusion criteria}

Players without ankle injury histories and players with ankle injury histories who had not participated at least one week of practice after injury was included in the study. Any individual who had intolerable pain during the measurement gaining procedures and subjects with a history of any fractures, current ankle injuries, neurological disorders, abnormal foot arches, foot deformities [8] were excluded from the study.

\subsection{Recruitment of participants}

Ethical clearance for the study was obtained from the ethical review committee of Kotelawala Defence University (KDU). Basketball players who fulfilled the inclusion and exclusion criteria were selected to take part in the research. All basketball players were provided with an information sheet containing all the necessary information regarding the procedures. The participants were provided more details regarding the study if requested. All the participants were given a consent form to obtain the written consent. The procedure and other relevant protocols of the study were clearly explained to participants and they were free to ask any question about the research. If any problems or complaints came related to the study the contact details of all investigators were given to the participants. Participants made their own decision whether to take part in the study, and they were also informed that their participation was not compulsory. All the participants were free to withdraw from the study at any given point.

\subsection{Data collection}

Data collection including taking measurements and recording was conducted by three trained investigators under the supervision of the research supervisor. After obtaining written and verbal consent the subjective information including demographic data, sport related data, and ankle injury history were obtained using Interviewer-administrated questionnaire. Players were asked to remove footwear before taking measurements. All the test measurements were taken in the same measurement place for all the players. WBDF measurements of all players were taken by the same investigator of the research group. Documentation of WBDF measurement was recorded by another investigator of the group. WBDF range was measured by weight bearing lunge test (WBLT). Table 1 shows demographics of the participants.

Table 1: Participant's demographics for the study

\begin{tabular}{|l|l|l|l|l|l|}
\hline & Male & Female & Injured & Uninjuted & Total \\
\hline Numr of participants & 36 & 28 & 17 & 47 & 64 \\
\hline
\end{tabular}

\section{Theory and Calculation}

\subsection{Weight Bearing Lunge Test}

WBLT was performed using an inclinometer, measuring the angle between the tibial shaft and the vertical. The angle was measured at $15 \mathrm{~cm}$ below the tibial tuberosity considering its excellent methodological quality, validity and reliability [9].

A reference line was marked on the wall using a tape on the floor and a corresponding vertical line on the wall, ninety (90) degrees perpendicular to the floor which was used to take measurements of all the participants. The lines remained during all testing sessions. A reference mark was drawn on the tibial shaft using a non-permanent marker at $15 \mathrm{~cm}$ below the tibial tuberosity on the anterior border of the tibia [10]. To get the WBDF measurement, the center of the inclinometer was placed on the reference mark, which ensured the accuracy of each measurement [10]. The test procedure was demonstrated, and standard instructions was given to the participant. The digital inclinometer was calibrated to zero (0) before taking each measurement by placing in on a flat surface. 
The participant was then instructed to place their hands on the wall in front of them and asked to lunge the front knee forward to touch the vertical line on the wall with their knee, while maintaining the heel contact with the ground to control the subtalar joint [11]. The contralateral limb was placed behind the testing limb and the toes was kept contacting the ground and the hip facing forward. The participant was then instructed to take the lunged foot further back from the wall to get the maximum WBDF prior to heel lift. At maximum range, the inclinometer was placed on the reference mark on the tibia and the measurement was noted. WBDF measurements were recorded in degrees. The test was repeated three times for each limb and the maximum measurement was recorded as it showed excellent reliability compared to taking an average value [12]. All the tests were performed by one researcher to minimize the handling errors.

\subsection{Data analysis}

Data entry and analysis was done using the SPSS (Statistical Package for Social Sciences) statistical analysis software, version 23. Descriptive analysis calculating mean standard deviation (SD) and 95\% confidence intervals (CI) for WBDF.

\subsection{Analysis of WBDF according to the gender}

Forty-seven uninjured were allocated in this analysis (male -24 and female -23 ) with descriptive data presented (Table 2). Descriptively, females showed smaller WBDF compared to males. Male group demonstrated slightly greater variability compared to the females (female- $45.7^{0} \pm 2.095 \% \mathrm{CI} 44.9^{0}, 46.6^{0}$, males- $46.6^{\circ} \pm 2.695 \%$ CI $\left.45.5^{\circ}, 47.6^{\circ}\right)$ However this difference was not statistically significant $(\mathrm{t}=1.26, \mathrm{p}=$ $0.2)$.

Table 2: Descriptive data objective 2 WBDF $\left({ }^{\circ}\right)$ in males and females

\begin{tabular}{|l|l|l|}
\hline & Male & Female \\
\hline Number & 24 & 23 \\
\hline Mean & 46.6 & 45.7 \\
\hline SD & 2.6 & 2.0 \\
\hline $95 \%$ CI & $45.5,47.6$ & $44.9,46.6$ \\
\hline
\end{tabular}

3.4 Comparison of the difference in WBDF between basketball players with a presence and absence of unilateral ankle injury

Thirteen participants had unilateral injury history (males - 10, females- 3). Descriptive data are displayed in Table 3. The difference between uninjured and injured limb the participants with unilateral ankle injury history was statistically significant (uninjured $47.2^{\circ} \pm 1.595 \% \mathrm{CI} 46.4^{0}, 48.0^{\circ}$, injured $44.3^{\circ} \pm 2.595^{\%} \mathrm{CI}$ $\left.43.0,45.6^{\circ}\right) \mathrm{t}$ value $\left.=-6.9, \mathrm{p}=0.001\right)$

Table 3: Descriptive data- unilateral injury history $W B D F\left({ }^{\circ}\right)$

\begin{tabular}{|l|l|l|l|}
\hline & Mean & SD & $95 \%$ CI \\
\hline Uninjured & 47.2 & 1.5 & $46.4,48.0$ \\
\hline Injured & 44.3 & 2.5 & $43.0,45.6$ \\
\hline
\end{tabular}

3.5 Comparison of the difference between WBDF AND the dominant and non-dominant limb

Seventeen participants were included for the analysis. The WBDF range of motions for Dominant limb and non- dominant $\operatorname{limb}\left(46.2^{\circ} \pm 2.595 \% \mathrm{CI} 45.2^{0}, 47.4^{0}, 45.5^{0} \pm 2.695 \% \mathrm{CI} 44.2^{0}, 46.7^{0}\right)$. The result was statistically significant $(\mathrm{t}-2.5, \mathrm{p}=0.02)$ as shown in Table 4 . 
Senanayake et al., Adv. J. Grad. Res.; Vol. 11, Issue 1, pp: 45-51, January 2022

Table 4: Paired sample statistics of dominant and non-dominant limb analysis for WBDF $\left(^{\circ}\right)$

\begin{tabular}{|l|l|l|l|}
\hline & Mean & SD & $95 \%$ CI \\
\hline Dominant limb & 46.2 & 2.5 & $45.2,47.4$ \\
\hline Non dominant limb & 45.5 & 2.6 & $44.2,46.7$ \\
\hline
\end{tabular}

\section{Results and Discussion}

Basketball is a popular sport all over the world played by both males and females. Ankle dorsiflexion movement occurs naturally during many lower limb tasks and the impact on this is high in basketball. Hence, Ankle injuries are the commonest type of injury among basketball players [13]. Prevalence of such injuries among basketball players are at $78.43 \%$ [14]. The main aim of our study was to explore the relationship between gender and ankle injury history of basketball players to WBDF. This is the first study to report WBDF in basketball players in Sri Lanka

Tummala et al., [15] have determined the relationship between gender and ankle injury history among basketball players, where they have concluded that prevalence of ankle injury among female players (43.2\%) were slightly higher compared to male males (35.9\%). Subjects aged over 16 years with mean age of 21.75 were included in our study and used to establish the connection between age and an increased prevalence of ankle injuries. Twenty (62.5\%) male players and twelve (37.5\%) female players were included. The mean values of WBDF ranges for males was $\left(46.6^{\circ} \pm 2.6\right)$ and for females it was observed at $\left(45.7^{0} \pm 2.0\right)$. According to the results there was smaller WBDF ranges in females more than the males. However, the difference was not significant $(\mathrm{p}=0.2)$. The results indicate the mean value of WBDF of basketball players in the entire study population to be $\left(45.4^{0} \pm 2.6\right)$. Previous research looking into this has concluded that there is a difference in WBDF range between males and females (Female: $45.1^{\circ} \pm 6.8$ ) (Male: 45.6 ${ }^{\circ} \pm 5.3$ ) [18]. Another study by Hosea et al., emphasizes that the risk for an ankle injury was significantly greater for female athlete $(\mathrm{p}<0.05)$ [19]. This difference of WBDF between males and females may be due to biological structural difference between the two genders or the verification of power and strength of the muscles. Similar in values were observed among gymnasts $\left(45.1^{0} \pm 6.0\right)$ [18] which used the same test procedure.

Lateral ligament complex is the most common among ankle injuries [15]. WBDF is a factor with assistance, which has a crucial impact on the landing mechanism. A study [16] [17] conducted by Hoch et al., and Zhang et al., to examine the relationship between single-legged landing biomechanics and WBDF range of motion in persons with chronic ankle instability found that the persons with low dorsiflexion demonstrated a more erect landing posture, especially during stiff landing. Prior studies done to observe the relationship between ankle injuries and WBDF among regular population has found that uninjured limbs have a larger WBDF than the injured limbs among elite artistic gymnasts [18].

Our next objective was to find the influence of ankle injury history to WBDF range. Recurrent ankle injuries occur in the ankle ligament laxity during balance and ankle plant flexion [20]. There were 15 players with ankle injury history. Two were excluded due to bilateral injuries. A total of thirteen participants had unilateral injury history (males in 10 and 03 in females). Mean value of WBDF ranges among injured players were $\left(44.3^{\circ} \pm 2.5\right)$ and it was $\left(47.2^{\circ} \pm 1.5\right)$ among contralateral uninjured players $(\mathrm{p}<0.05)$. The result suggests that injured limb had a smaller WBDF compared to contralateral uninjured limb.

Study conducted by Miller, Fawcett and Rushton [18] had conducted a study to explore the relationship between weight bearing dorsiflexion and ankle injury history among elite artistic gymnasts. Among 55 participants, the mean of WBDF of injured gymnasts were $\left(45.1^{0} \pm 6.0\right)$ and it was observed to $\left(47.4^{0} \pm 5.7\right)$ among uninjured gymnasts. The result in WBDF to injured and uninjured limb was statistically significant $(\mathrm{p}=0.003)$. The difference between WBDF and ankle injury history may be due to the anatomical structural damage, or it could be due to not having enough treatment for longer period of time, or it could be simply due to the influence in functional activity in the lower limb. Backman and Danielson [21] had done a study 
to examine the relationship between the patellar tendinopathy and ankle range of motion with seventy-five elite basketball players. They have concluded that the low range of ankle dorsiflexion has significant influence to developing patellar tendinopathy.

Furthermore, the results of our study showed that the mean WBDF in the dominant limb was $46.2^{\circ} \pm 2.5$ and the mean value in the non-dominant limb was $45.5^{\circ} \pm 2.6$. In the study conducted by Miller, Fawcett and Rushton [18] have mentioned that limb dominance is an important factor, which should be included in future research designs on the topic of WBDF. Halabchi et al., [22] had observed a58.5\% ankle injury prevalence among basketball players in their dominant leg. A study conducted by E Dolan and R Gordon [23] among football players, where the kicking leg was used as the dominant leg found no clinical significance in leg dominance and asymmetries in ankle dorsiflexion. According to our study there is difference between dominant and non-dominant limb WBDF range $(t=2.5)(p<0.05) t=2.5, P=0.02)$

The result of our study suggests that even the basketball players who takes part in competitions and practices still display a deficit in WBDF range between limbs. Hence, caution should be taken in evaluating $100 \%$ symmetry and ranges in motion after a basketball player returns to the full training following an injury and this is highly important when it comes to improving their performance through improvements in running, jumping and in changing in direction.

Ankle WBDF range of motion reduction can be a main factor to reduction of sport performance. These findings may influence clinicians in return to training and activity selection as with return to performance (RTP), planning, decision making. Decision of returning to the play should centre around functional range which influence to sport performance and activities of the player.

\section{Conclusions}

This is the first study to investigate WBDF among basketball players. Study provides normative data for the population, determining that males have larger WBDF range comparing to females. However, the difference was not statistically significant. The study demonstrated that injured players have a smaller WBDF range of motion in the ankle comparing to uninjured ankle. There is a strong involvement in dominancy of the limbs because the difference of dominant and non-dominant limb WBDF is statistically significant. Finally, the finding suggests the importance of identifying the risk of injury and RTP and planning among basketball players. Our study has contributed to fill the knowledge gap on WBDF and its variations among basketball players, where we found a significant difference in WBDF range of motion among the players who had previous ankle injury history.

\section{Declarations}

\subsection{Study Limitations}

The study has limited by the sample size of basketball players due to the COVID-19 pandemic situation prevailed in Sri Lanka during the data collection process. Therefore, with a larger sample size would have given us better, statistically significant results. The study revealed statistically significant difference between uninjured and injured limbs. However, the study did not examine the minimal perceptible change in this population.

\subsection{Ethical Approval}

Ethical approval was given by the ethical review committee, Faculty of Medicine, General Sir John Kotelawala Defence University. Approval number RP/S/2020/29

\subsection{Informed Consent}

Informed written and verbal consent was taken from all participants for the research as well as publications.

\subsection{Competing Interests}

There are no conflicts of interest exist for this publication. 


\section{How to Cite this Article:}

S. Senanayake, T. Premakumara, P. Kodagoda, and H. Jayasekara, "Influence of Weight Bearing Dorsiflexion (WBDF) on Ankle Injury History Among Semi-professional Recreational Basketball Players", Adv. J. Grad. Res., vol. 11, no. 1, pp. 45-51, Nov. 2021. https://doi.org/10.21467/ajgr.11.1.45-51

\section{References}

[1] CV Andreoli, BC Chiaramonti,E Biruel, A de Castro Pochini,B Ejnisman, M Cohen . Epidemiology of sports injuries in basketball: integrative systematic review. BMJ open sport \& exercise medicine. 2018 Dec 1;4(1):e000468.

[2] HT Van Der Does, MS Brink, A Benjaminse, C Visscher, KA Lemmink. Jump landing characteristics predict lower extremity injuries in indoor team sports. International journal of sports medicine. 2016 Mar;37(03):251-6.

[3] J Mateos Conde, MT Cabero Morán,C Moreno Pascual . Prospective Epidemiological Study of Basketball Injuries During One Competitive Season in professional and amateur Spanish basketball. The Physician and Sportsmedicine, 2021. https://doi.org/10.1080/00913847.2021.1943721

[4] CE Gross, JB Goodloe, JA Nunley. Management of Chronic Ankle Instability in the Basketball Player. InBasketball Sports Medicine and Science 2020 (pp. 459-466). Springer, Berlin, Heidelberg.

[5] RM van Rijn, J van Ochten, PA Luijsterburg,M van Middelkoop, BW Koes, SM Bierma-Zeinstra. Effectiveness of additional supervised exercises compared with conventional treatment alone in patients with acute lateral ankle sprains: systematic review. Bmj. 2010 Oct 26;341.

[6] LA Borowski, EE Yard, SK Fields, RD Comstock. The epidemiology of US high school basketball injuries, 2005-2007. The American journal of sports medicine. 2008 Dec;36(12):2328-35.

[7] CL Brockett, GJ Chapman. Biomechanics of the ankle. Orthopaedics and trauma. 2016 Jun 1;30(3):232-8.

[8] J Burns, J Crosbie. Weight bearing ankle dorsiflexion range of motion in idiopathic pes cavus compared to normal and pes planus feet. The Foot. 2005 Jun 1;15(2):91-4.

[9] CJ Powden, JM Hoch, MC Hoch. Reliability and minimal detectable change of the weight-bearing lunge test: a systematic review. Manual therapy. 2015 Aug 1;20(4):524-32.

[10] A Cejudo, PS de Baranda,F Ayala, F Santonja . A simplified version of the weight-bearing ankle lunge test: Description and testretest reliability. Manual therapy. 2014 Aug 1;19(4):355-9.

[11] K Bennell , R Talbot, H Wajswelner, W Techovanich, D Kelly, AJ Hall. Intra-rater and inter-rater reliability of a weight-bearing lunge measure of ankle dorsiflexion. Australian Journal of physiotherapy. 1998 Jan 1;44(3):175-80.

[12] MD Chisholm, TB Birmingham, J Brown, J MacDermid, BM Chesworth. Reliability and validity of a weight-bearing measure of ankle dorsiflexion range of motion. Physiotherapy Canada. 2012 Oct;64(4):347-55.

[13] $\mathrm{H} \mathrm{Hu}$. Common types and countermeasures of ankle ligament injury caused by intense basketball movement. Nigerian journal of clinical practice. 2017 Sep 15;20(8):1036-9.

[14] TJ Ellapen, S Narsigan, FM Essack, P Jugroop, NA Macrae, J Milne, C Stow , HJ Van Heerden. Prevalence of basketball-related musculoskeletal injuries among university players: biokinetics practice and sport injuries. African Journal for Physical Health Education, Recreation and Dance. 2012 Jun 1;18(2):308-16.

[15] SV Tummala, DE Hartigan, JL Makovicka, KA Patel,A Chhabra . 10-year epidemiology of ankle injuries in men's and women's collegiate basketball. Orthopaedic journal of sports medicine. 2018 Oct 31;6(11):2325967118805400.

[16] MC Hoch, KE Farwell, SL Gaven, JT Weinhandl. Weight-bearing dorsiflexion range of motion and landing biomechanics in individuals with chronic ankle instability. Journal of athletic training. 2015 Aug;50(8):833-9.

[17] SN Zhang, BT Bates, JS Dufek. Contributions of lower extremity joints to energy dissipation during landings. Medicine and science in sports and exercise. 2000 Apr 1;32(4):812-9.

[18] H Miller ,L Fawcett,A Rushton . Does gender and ankle injury history affect weightbearing dorsiflexion in elite artistic gymnasts? Physical Therapy in Sport. 2020 Mar 1;42:46-52.

[19] TM Hosea,CC Carey, MF Harrer. The gender issue: epidemiology of ankle injuries in athletes who participate in basketball. Clinical Orthopaedics and Related Research®. 2000 Mar 1;372:45-9.

[20] CR Denegar, J Hertel, J Fonseca . The effect of lateral ankle sprain on dorsiflexion range of motion, posterior talar glide, and joint laxity. Journal of Orthopaedic \& Sports Physical Therapy. 2002 Apr;32(4):166-73.

[21] LJ Backman,P Danielson. Low range of ankle dorsiflexion predisposes for patellar tendinopathy in junior elite basketball players: a 1-year prospective study. The American journal of sports medicine. 2011 Dec;39(12):2626-33.

[22] LJ Backman, P Danielson. Low range of ankle dorsiflexion predisposes for patellar tendinopathy in junior elite basketball players: a 1-year prospective study. The American journal of sports medicine. 2011 Dec;39(12):2626-33.

[23] Dolan K E, Gordon J R, Hummel C, McKeon P O. "Exploring the effects of limb dominance and injury history on weight-bearing dorsiflexion asymmetry: A Clinical Case Series”. National Athletic Trainers' Association Clinical Symposia, Las Vegas, NV, June 2019.

\footnotetext{
Publish your books with AIJR publisher-

- Publish with ISBN and DOI.

- Publish Thesis/Dissertation as Monograph.

- Publish Book Monograph.

- Publish Edited Volume/ Book.

- Publish Conference Proceedings

- Retain full copyright of your books.

Submit your manuscript at books.aijr.org
}

Publish your research article in AIJR journals-

- Online Submission and Tracking

- Peer-Reviewed

- Rapid decision

- Immediate Publication after acceptance

- Articles freely available online

- Retain full copyright of your article.

Submit your article at journals.aijr.org 